College of Veterinary Medicine and Animal Production, Sudan University of Science and Technology.

\title{
PREGNANCY DIAGNOSIS AND FETAL QUANTIFICATION IN DAMASCUS GOATS USING TRANSABDOMINAL REAL-TIME ULTRASONOGRAPHY
}

(With 3 Figures)

\author{
By \\ RIHAB M. ABDELGHAFAR; SAFAA A. ABDALLAH* \\ and B.H. AHMED** \\ * Ministry of Agriculture, Animal Wealth and Irrigation, Khartoum State \\ ** Institute of Radiotherapy and Nuclear Medicine, \\ The National Rabat University. \\ (Received at 2/9/2009)
}

\section{SUMMARY}

The assessment of an early and reliable pregnancy diagnosis in goats is very important for limiting the number of non productive days in goat herds. The present study was conducted to detect pregnancy and to estimate fetal quantification in a flock of Damascus goats. A total of thirty multiparous Damascus goats were used in the present study. They were divided into three groups according to their estimated date of gestation. Group $1(n=9)$ was between 21-35 days of gestation, group 2 $(n=10)$ was between 36-55 days of gestation and the third group $(n=11)$ was between 56-75 days of gestation. Transabdominal ultrasound scanning was done while the animal was on a dorsal recumbancy and well restrained with a pillow put underneath. Real-time ultrasound scanner equipped with switchable frequency (5-7.5 MHz) micro convex probe was used in the study. The overall accuracy for pregnancy diagnosis was $100 \%$. The accuracy for fetal quantification for all predictions was found to be $90.9 \%$. The overall accuracy for determining single fetuses, twins and triplets was 100, 85.7 and $50 \%$ respectively. It is concluded that ultrasound is a safe, rapid and reliable method in detecting pregnancy and estimating fetal quantification in Damascus goats.

Key words: Damascus, Ultrasound, Pregnancy diagnosis, Fetal quantification 


\section{INTRODUCTION}

Reproductive assessment plays an important role in production improvement, because most reproductive failures are due to death during pregnancy or due to pregnancy expectations in females with false pregnancy (Azevedo et al., 2007). Real time ultrasound in small ruminants offers an unparalleled range of information regarding pregnancy status, number of fetuses and gestational age (Haibel 1990). Early diagnosis of pregnancy and determination of fetal numbers are of considerable value in goat reproductive management (Martinez et al., 1998). Discriminating between pregnant and non- pregnant animals would allow early culling or rebreeding of barren does (Gonzalez et al., 2004). The distinction of single and multiple fetuses allows the breeder to provide a more adequate nutritional management at the end of gestation (Dias et al., 2009). Transabdominal ultrasound represents the best available method for a sure, easy and reliable pregnancy diagnosis in goats (Santos, et al., 2006). In addition to pregnancy diagnosis, accurate information on the stage of pregnancy would be useful to dry off lactating females and to monitor females near term (Oral, et al., 2007). The aim of the present study was to detect pregnancy and to determine fetal quantification in a flock of Damascus goats.

\section{MATERIALS and METHODS}

Animals: A total of thirty multiparous Damascus goats (2-5 years old, weighting between $35-60 \mathrm{kgs}$ ) were used in the present study. They were kept within the premises of Khartoum Livestock Genetics Improvement Center, Ministry of Agriculture, Animal Wealth and Irrigation, Khartoum State. They were fed Alfa Alfa hay ad libitum and a mixture of (Wheat brand, Sesame cake, Ground nut cake and Sorghum), with free access to water and minerals blocks supplement. Estrus was carefully observed by daily introducing a teaser buck (that was not allowed to mate). A doe showing an estrus sign was artificially inseminated using fresh semen collected from a proven fertile buck. The day of introducing the buck was designated as day 0 of gestation. Upon the extension of estrus for two days the animal will be re inseminated. Animals were divided into three groups according to their recorded insemination date. Group 1 consisted of nine does with gestational age between (21-35) days. Group 2 consisted of ten does with gestational 
age between (36-55) days. The third group consisted of eleven does with gestational age between (56-75) days.

Animal preparation: Animals were fasted for 12 hours prior to scanning to avoid accumulation of gases in the gastrointestinal tract; however water was allowed ad libitum. The ventral abdomen was clipped and shaved carefully. Animals were layed on their backs (dorsal recumbancy), with a pillow put underneath as described previously by (Abdelghafar, 2006). Liberal amount of ultrasonic gel (Sonogel vet ${ }^{\circledR}$ Germany) was applied to the ventral abdomen prior to the scanning. Ultrasound scanning: Only single ultrasound examination was performed on each goat simulating field exam conditions using a realtime scanner (Easote Pie Medical, Holland) equipped with switchable frequency $(5-7.5 \mathrm{MHz})$ micro convex probe. Images were stored in the memory card, and later they were printed in a thermal papers using special printer (Sony- Japan). Sagittal, parasagittal, cross and cross oblique sections were obtained to ascertain accurate diagnosis

Data analysis: The sensitivity, specificity, and overall accuracy were calculated according to (Baronet and Vaillancourt 1984). Sensitivity was defined as the number of confirmed positive diagnosis divided by the total number of positive diagnosis. Specificity was defined as the number of confirmed negative diagnosis divided by the total number of negative diagnosis. Accuracy was defined as the number of confirmed diagnosis (pregnant and non-pregnant) divided by the total number of females diagnosed.

\section{RESULTS}

A doe is considered pregnant when fluid-filled gestational sac with fetal parts was demonstrated, as shown in (Fig. 1), (Fig.2) and (Fig. 3). The overall accuracy for pregnancy diagnosis was $100 \%$. Out of thirty does twelve were diagnosed as pregnant (Sensitivity 100\%) and eighteen as non-pregnant (Specificity 100\%). In group 1 two animals were diagnosed as positive and seven as negative with $100 \%$ accuracy. In group 2 three animals were diagnosed as positive and seven as negative with $100 \%$ accuracy. In group 3 seven animals were diagnosed as positive and four as negative with $100 \%$ accuracy, the golden standard test was the delivery.

Regarding fetal quantification out of twelve pregnant does only eleven were subjected to fetal quantification and one does went unnoticed. The accuracy of ultrasound for fetal quantification in all predictions for the three groups was $90.9 \%$. One doe bearing triplet 
fetuses was erroneously diagnosed as bearing twins. The accuracy for detecting single fetuses, twins and triplets was 100\%, 85.7\% and 50\% respectively. In group 1 the two pregnant does were diagnosed as bearing twins with $50 \%$ accuracy; this is due to that one doe bearing triplet fetuses was falsely diagnosed as bearing twins. In group 2 out of the three positive does, two does were diagnosed as bearing twins and one doe as bearing single fetus with $100 \%$ accuracy. Concerning fetal quantification in the third group, two does were diagnosed as bearing single fetus, three does as bearing twins and one doe as bearing triplets fetuses with $100 \%$ accuracy; one doe went unnoticed.

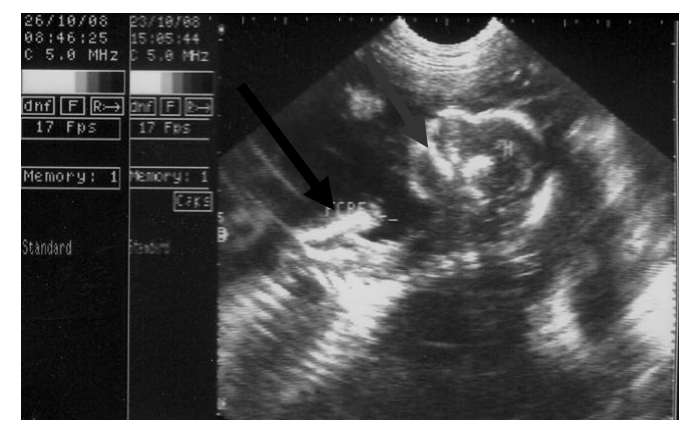

Fig. 1: Fetus. Realize the fore limb (Black arrow) and the mouth (Gray arrow)

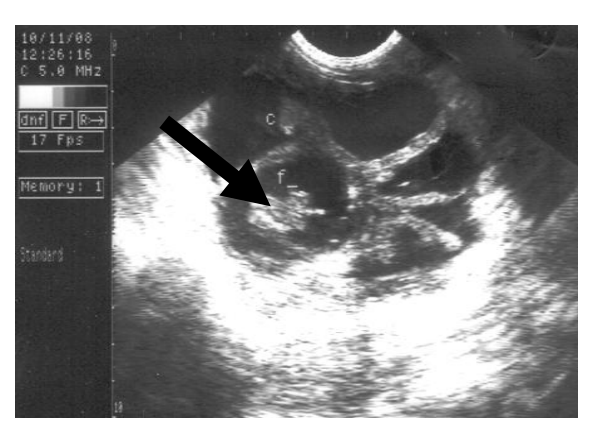

Fig. 2: Gestational sacs with fetus at day 35 of gestation (Arrow)

Fig. 3: Twins at day 60 of gestation (Arrows) 


\section{DISCUSSION}

To the authors' knowledge this is the first report in the country concerning the use of ultrasound in detecting pregnancy and estimating fetal numbers in Damascus goats. Collectively results from this study demonstrate clearly that the use of real-time transabdominal ultrasound is a highly accurate technique for pregnancy diagnosis. The relatively low proportion of pregnancies among observed animals could be related to many factors including exportation of these animals from abroad and they were not well adapted at that time. The overall accuracy for pregnancy diagnosis was found to be $100 \%$. This is in accordance with our previous findings in Saanen goats (Abdelghafar et al., 2007). Anwar et al. (2008) reported $100 \%$ accuracy for pregnancy diagnosis by using transabdominal ultrasonography in Balkhi sheep at 42 days of gestation and $97 \%$ accuracy at day 75 of gestation. Concerning fetal quantification the overall accuracy for all predictions for the three groups was found to be $90.9 \%$. One doe bearing triplets was falsely diagnosed as bearing twins, and this may be due to that in multiparous goats the uterus has many folds which overlaps and the fetus which measured only about 1 $\mathrm{cm}$ at (21-35) days of gestation may be overlooked. Abdelghafar et al (2007) reported overall accuracy in fetal quantification about $79.3 \%$ and found that the accuracy for detecting single fetuses, twins and triplets was $83.3,77.7$ and $50 \%$ respectively. Increased accuracies in the present study were due to that the author obtained more experiences. Dawson et al. (1994) reported 44, 73 and 67\% accuracy for determining singles, twins and triplets respectively at 5 weeks of gestation and 82, 89 and $100 \%$ accuracy at 7 weeks of gestation in alpine does using transabdominal real-time ultrasonography. Although Goel and Agrawal (1992) reported that it is difficult to differentiate twins from triplets or quadruplets at any stage of gestation, in the present study we could differentiate triplets from twins at (56-75) days of gestation.

Many factors enhances the accuracy of the technique, firstly, scanning in a dim-light room helped to obtain high quality images, as working in a lighted place usually gives poor images in the screen. Fasting of the animal, clipping and shaving of the skin both would exclude air from the gastrointestinal canal and the skin respectively which seems to be the enemy of ultrasound transmission. Karen et al. (2004) reported that fasting 12 hours prior to the scanning significantly improved the accuracy of ultrasonographic pregnancy diagnosis in ewes. 
Putting the animal in its back with a pillow underneath, offers high comfort for the animal as well as for the operator.

Using the transabdominal approach provided a wide area for examining the fetus, as in late stages the fetuses enlarged and extended to the abdomen and could easily be reached by a transabdominal approach. Using a micro convex probe with a wide near field that enhances displaying of a large area of the uterus. It is concluded that ultrasound was found to be a non-invasive, non-time consuming, possesses no apparent risk to health and makes possible a more accurate pregnancy diagnoses and fetal quantification.

\section{ACKNOWLEDGMENT}

The staff and administrative of the Khartoum Livestock Genetics Improvement Center are greatly acknowledged for providing the experimental animals and all the facilities for the study.

\section{REFERENCES}

Abdelghafar, R.M. (2006): Pregnancy diagnosis and fetometry in Saanen goats using real- time ultrasonography. M. Sc. Thesis, Sudan University of Science and Technology. pp 71.

Abdelghafar, R.M.; Bakheit, A.O. and Ahmed, B.H. (2007): B- Mode real-time ultrasonography for pregnancy diagnosis and fetal numbers in Saanen goats. Journal of Animal and Veterinary Advances 6(5): 702-705.

Anwar, M.; Riaz, A.; Ullah, N. and Rsfig, M. (2008): Use of ultrasonography for pregnancy diagnosis in Balkhi sheep. Pakistan Vet. J. 28 (3): 144-146.

Azevedo, E.M.; Aguiar Filho, C.R.; Freitas Neto, L.M.; Rabelo, M.C.; Santos, M.H.; Lima, P.F.; Freitas, V.J. and Oliveira, M.A (2007): Ultrasound fetal measurement parameters for early estimate of gestational age and birth weight in ewe. Medicina Veterinaria, (1): 2 pp 56-61.

Baronet, D. and Vaillancourt, D. (1984): Diagnostic de gestation par echotomographie chez la chevre. Medicine Veterinaire Quebec, 19: 67-72.

Dawson, L.J.; Sahlu, T.; Hart, S.P.; Detweiler, G.; Gipson, T.A.; Teh, T.H. Henry, G.A. and Bahr,R. J (1994). Determination of fetal numbers in alpine does by real time ultrasonography. Small Ruminant Research 14: 225-231. 
Dias, L.M.; De Souza, J.C.; Assis, R.D. and Raymundo, C.D. (2009): Pregnancy diagnosis, fetal quantification and gender estimation by ultrasonography in ewes. Cience Agrotecnologica, (33): 3 pp 56-61.

Goel, A.K. and Agrawal, K.P. (1992): A review of pregnancy diagnosis techniques in sheep and goats. Small Ruminant Research, 9: 255-264.

Gonzalez, F.; Cabrera, F.; Batista, M.; Rodriquez, N.; Alamo, D.; Sulon, J.; Beckers, J. and Anselmo, G. (2004): A comparison of diagnosis of pregnancy in the goat via transrectal ultrasound scanning, progesterone, and pregnancy-associated glycoprotein assays. Theriogenology. 62: 1108-1115.

Haibel, G.K. (1990): Use of ultrasonography in reproductive management of sheep and goat herds. Veterinary Clinics of North America Food Animal Practice 6 (3): 597-613.

Karen, A.; Szabados, K.; Reiczigel, J.; Beckers, J. and Szenci, O. (2004): Accuracy of transrectal ultrasonography for determination of pregnancy in sheep: effect of fasting and handling of the animals. Theriogenology, 61: 1291-1298.

Martinez, M.F.; Bosch, P. and Bosch, R.A. (1998): Determination of early pregnancy and embryonic growth in goats by transrectal ultrasound scanning. Theriogenology, 49: 1555-1565.

Oral, H.; Pancarci, S.M.; Gungor, O. and Kacar, C. (2007): Determination of gestational age by measuring fetal heart diameter with transrectal ultrasonography in sheep. Medycyna Wet. 63 (12) 1558-1560.

Santos, M.H.; Moura, R.T.; Chaves, R.M.; Soares, A.T.; Neves, J.P.; Reichenbach, H.D.; Lima, P.F. and Oliveira, M.A. (2006): Sexing of Boer goat fetuses using transrectal ultrasonography. Animal Reproduction. (3): 3, 359-363. 